\title{
Pathways of preferential atrial conduction
}

Sir,

We read with both interest and concern the account of Dr T N James (1984; 52: 1-23) concerning the debate on the anatomical substrates for internodal conduction. From his review, we draw the inference that he believes the issue to have been clouded by workers such as ourselves. ${ }^{1}$ This is because, following the precedent set at a meeting of the German Pathological Society in $1910,{ }^{2}$ we have suggested that the model for an anatomically discrete conduction system should be the insulated series of tracts found within the ventricular myocardium. In raising this matter, Dr James must be aware that, after his own initial paper, ${ }^{3}$ some distinguished cardiologists ${ }^{4}$ came to accept that such a system of tracts did exist within the atrial myocardium. Furthermore, these "tracts" have been illustrated in books prepared for "general consumption"s-7 in a fashion analogous to the ventricular bundle branches. As Dr James knows well, there is no anatomical evidence for the existence of such insulated tracts in the atrial tissues. It is significant in this respect that his own diagrams of the pathways have changed from the single solid lines of his 1963 drawing $^{3}$ to the more vague discontinuous lines of his present figure (Fig. 4, p.5). Yet even now we are unaware of any anatomical evidence that shows that the atrial myocardium in the areas he illustrates as "pathways" is any different morphologically and histologically from that elsewhere in the atrial wall and septum. This is particularly so in the case of his "middle pathway," which seems to pass directly through the site of the oval fossa. Dr James accuses us of raising a straw man when we discuss the specialisation of the atrial myocardium. We plead not guilty to this charge. But is he not guilty of this offence when he raises the matter of the structure of the sinus node? The sinus node is primarily designed to generate the impulse. Although its cells must then also conduct, they do not have conduction as a primary function, as do the ventricular bundle branches. He goes on to construct another straw man when he argues that these ventricular bundle branches themselves are composed of several cell types. Here, and elsewhere, he misses the whole point of our argument. Irrespective of their cellular composition, the ventricular bundle branches can be traced through serial histological sections because they are insulated from the ventricular myocardium. If the tissue within the insulating sheaths is divided conduction into the ventricles ceases. This is certainly not the case with the atrial myocardium. Dr James then raises a third straw man concerning the specialised action potentials of atrial cells. There is no doubt that there are several populations of cells in the atrial tissues that have different action potential configurations. There is also evidence that "sinoventricular conduction" can occur when the atrial myocardial cells themselves are paralysed. But we know of no evidence that has shown that those cells with specialised potentials conduct any more rapidly than the "working" cells nor that an anatomically discrete system of atrial cells is responsible for sinoventricular conduction. The only paper of which we are aware that investigated the morphology of these cells showed that both specialised and working potentials originated from areas of plain atrial myocardium. ${ }^{8}$ Furthermore, as Dr James himself states, the recent work of Spach and his colleagues ${ }^{9}$ has shown that the simple geometry of the atrial septum accounts fully for preferential conduction between the nodes. If, Sir, the histological appearance and constituents of the atrial cells also are involved in this process of preferential conduction, it is incumbent upon Dr James to produce the evidence supporting this rather than obfuscating the topic still further with skilful rhetoric.

Robert H Anderson, *

Anton E Becker, $\dagger$

${ }^{\star}$ Cardiothoracic Institute,

Brompton Hospital,

Fulham Road,

London SW3 6HP.

†Department of Pathology,

Academisch Medisch Centrum,

Meibergdreef 9 ,

$1105 \mathrm{AZ}$ Amsterdam,

The Netherlands.

\section{References}

1 Anderson RH, Becker AE. Anatomy of conducting tissues revisited. Br Heart $\mathcal{f}$ 1978; 40 (suppl): 2-16.

2 Anonymous. Bericht über die Verhandlungen der XIV Tagung der Deutschen pathologischen Gesellschaft in Erlangen vom 4-6 April 1910. Zentralblatt für allgemeine Pathologie und pathologische Anatomie 1910; 21: 433-8.

3 James TN. The connecting pathways between the sinus node and $\mathrm{A}-\mathrm{V}$ node and between the right and the left atrium in the human heart. Am Heart f 1963; 66: 498508.

4 Bigger JT Jr. Electrophysiology for the clinician. Eur Heart f 1984; 5 (suppl B): 1-9.

5 Netter FH. In: The heart. The Ciba Collection of Medical 
Ilustrations. vol 5. Summit, NJ: Ciba Phamaceutical Co, 1969: 13.

6 Huszar RJ. Emergency cardiac care. 2nd ed. Bowie, Maryland: Robert J Brady, 1982: 145.

7 Watson H. Disorders of cardiac rate, rhythm and conduction. Beaconsfield, Bucks: Beaconsfield Publishers Ltd, 1984: 7.

8 Tranum-Jensen J, Janse MJ. Fine structural identification of individual cells subjected to microelectrode recording in perfused cardiac preparations. $\mathcal{F} \mathrm{Mol}$ Cell Cardiol 1982; 14: 233-47.

9 Spach MS, Kootsey JM. The nature of electrical propagation in cardiac muscle. Am $\mathcal{F}$ Physiol 1983; 244: H3-22.

This letter was shown to the author, who replies as follows:

Sir,

Thank you for the privilege of responding to the letter from Drs Anderson and Becker. Much of their concern now and in the past has to do with the purported insulation of the internodal pathways, but it is unclear why they address their criticisms to me. As they very well know, I have never said or written that these pathways are shielded or insulated in any way. The reason my original drawing which showed solid lines has been changed to one with interrupted dashes (Fig. $4, \mathrm{p} \mathrm{5}$ ) (which I do not believe are "vague") is to encourage others not to misinterpret this matter. Drs Anderson and Becker indicate that they are unaware of anatomical evidence that the atrial myocardium in the internodal pathways is different, choosing to ignore Figs. 5 and 6 (p 6 and 7) as well as the work cited in my references $27,31,33,39,40,43,44,55$, and 62 (p 20 and 21). Cardiac anatomists as experienced as Maurice Lev and Lino Rossi find no difficulty in identifying the preferential internodal pathways. Drs Anderson and Becker suggest that the middle internodal pathway appears to pass through the fossa ovalis, but my original description and that of all other subsequent investigators (for example, see Figs. 8,9 , and 10 in reference 4 cited by them) have explained how it combines with the descending portion of the anterior internodal pathway within the torus Loweri, which forms the anterior margin of the fossa ovalis. They accuse me of missing their point, when I emphasise that the bundle branches include more than one cell type, but what the latter fact indicates is that we have a long way to go in understanding the precise function of any of the wide variety of cells present in the myocardium, including the bundle branches. Their comment that the bundle branches can be traced in serial sections is true only for their proximal portion. No one to my knowledge has been able to trace much more than the first 20 or $30 \mathrm{~mm}$ of the course of the human left bundle branch nor of the right branch once it leaves the moderator band. They say that division of a bundle branch causes conduction into the ventricles to cease, which is simply not true. One can divide the right branch experimentally or demonstrate its complete interruption by disease in man, but the right ventricle still becomes activated, although about $20 \mathrm{~ms}$ more slowly. Evaluating either experimental or postmortem evidence of the effects from division of the left bundle branch is considerably more difficult, as Lenegre and others long ago demonstrated, but it is probable that complete interruption of it is still associated with activation $(20$ or $30 \mathrm{~ms}$ delayed) of the left ventricle. Following their erroneous statement that interrupting a bundle branch would terminate conduction to the ventricle, they say "this is certainly not the case with the atrial myocardium." But observations cited in my references 23 , $32,35,37,39,53,57$, and 64-66 (p 20 and 21 ) offer evidence to the contrary: interruption of these pathways does delay atrial conduction. In referring to the work of Spach and his colleagues (my reference 58) I did not write that geometric histology fully accounts for preferential conduction but that it was a valid component of that explanation. Both older research (my references $51,52,60$, and 61 ) as well as that more recent $(59,72$, and 73$)$ support the concept of preferential conduction via internodal pathways in the atria, including its participation in atrial flutter. Thus, Sir, it is the evidence which Drs Anderson and Becker choose to ignore which may be the explanation of why they continue to find the topic obfuscating.

Thomas $\mathrm{N}$ James,

Callaway Laboratory of the Department of Medicine, University of Alabama Medical Center, Birmingham, Alabama 35294, USA. 